\title{
Blog da Petrobras: novas relações entre jornalista e fonte?
}

\author{
Victor Gentilli ${ }^{1}$ \\ (vgentilli@uol.com.br) \\ http://dx.doi.org/10.5216/cei.v15i1.22508
}

\begin{abstract}
Resumo
Em maio de 2009, houve uma intensa polêmica com a decisão da Petrobras de criar um blog chamado Fatos e Dados para, não apenas divulgar suas atividades como também responder, publicamente, a questões colocadas por jornalistas em matérias ainda em processo de apuração. O Estado de S. Paulo, a Folha de S. Paulo e $O$ Globo criticaram duramente a iniciativa. Este artigo faz uma revisão bibliográfica sobre os trabalhos produzidos sobre o polêmico blog Fatos e Dados criado em 2009 pela Petrobras e análise da relação atual da empresa com os veículos de imprensa. Observou-se que a empresa continua divulgando perguntas e respostas dos jornalistas, mas apenas de jornais nacionais excluídas as entrevistas exclusivas e em off. Outras instituições não procedem da mesma forma.
\end{abstract}

Palavras-chave: Fontes. Petrobrás. Jornalismo.

\begin{abstract}
In May 2009, there has been an intense controversy with the Petrobrás decision to create a blog called Facts and data for, not just publicize your activities but also respond publicly to questions posed by journalists on matters still under investigation. O Estado de S. Paulo, Folha de S. Paulo and O Globo criticized harshly the initiative. The article make the literature review on the work produced on the controversial blog Fatos e Dados (Facts and data) created in 2009 by Petrobrás and current analysis company with the media. It was noted that the company continues promoting journalists ' questions and answers, but only of national newspapers excluded the exclusive interviews and off. Kay-words: Sources, Petrobrás, journalism.
\end{abstract}

Keywords: Sources. Petrobrás. Journalism.

\section{Introdução}

Em maio de 2009, houve uma intensa polêmica com a decisão da Petrobras de criar um blog chamado Fatos e Dados para, não apenas divulgar suas atividades como também responder, publicamente, a questões colocadas por jornalistas em matérias ainda em processo de apuração. $\mathrm{O}$ Estado de S. Paulo, a Folha de S. Paulo e $O$ Globo criticaram duramente a iniciativa. A Associação Nacional de Jornais (ANJ) igualmente condenou a empresa argumentando que tal iniciativa resultaria "numa inaceitável quebra da confidencialidade que deve orientar a relação entre

\footnotetext{
1 Doutor em ciências da comunicação pela Universidade de São Paulo (USP), Professor associado dos programas de graduação e pós-graduação em comunicação da Universidade Federal do Espírito Santo (Ufes), Brasil, Espírito Santo, Vitória.
} 
jornalistas e suas fontes”. A Associação Brasileira de Imprensa (ABI) apoiou a estatal, assim como vários profissionais. Houve um intenso debate em sites sobre imprensa, mídias sociais e blogs.

Entre o final de 2009 e o ano de 2011, pouco mais de dois anos, foram identificados, 20 trabalhos acadêmicos em que o assunto se constituía em objeto de estudo, como se pode ver nas referências. Destes, um capítulo de livro, seis artigos em publicações científicas, oito papers apresentados em eventos, dois trabalhos de Conclusão de Cursos, dois trabalhos de Iniciação Científica (IC) apresentados em eventos e um trabalhos de Iniciação Científica. A iniciativa despertou intenso interesse e foi esmiuçada. Todos tinham um olhar simpático à iniciativa e viam nele uma mudança na relação jornalista-fonte.

O blog Fatos e Dados teve três fases. Foi criado em 2 de junho de 2009 na plataforma wordpress, com a novidade de publicar as perguntas e as respostas encaminhadas a jornalistas antes mesmo da publicação das matérias pelos jornais. No dia 10 de junho, a empresa passa a publicar as respostas à zero hora do dia em que a matéria será publicada. Em 4 de julho de 2009, o blog migra para provedor próprio e passa a funcionar onde permanece até hoje. Mesmo publicando as respostas no mesmo dia da publicação das matérias, o blog permaneceu agressivo. Em três ocasiões, questionou jornais. Os dois primeiros em dois dias seguidos, ao jornal O Globo e ao Correio Brasiliense.

No dia 25 de junho de 2009 o blog interpelou o jornal $O$ Globo:

"Desde ontem a Petrobras vem tentando obter, e não conseguiu até o presente momento, alguma informação a respeito do inquérito sobre o o"dossiê das ambulâncias". Esse inquérito se encontra no Ministério Público Federal de Cuiabá, sob a responsabilidade do procurador Mario Lucio Avelar. Como o jornal O Globo conseguiu informações?”

No dia 26 de junho de 2009, o blog interpelou o Correio Brasiliense:

“A Petrobras gostaria de saber do jornal Correio Braziliense como conseguiu as informações sobre bens patrimoniais de diretores da Companhia, que constam de sua matéria publicada em 25/06/2009 sob o título “Os xeiques da Petrobras".

A terceira interpelação se dará já em 2010 no contexto da campanha eleitoral. A Petrobrás respondeu a Lauro Jardim, colunista de Veja, que postou no twitter e publicou no site uma informação de que a empresa teria contratado uma pesquisa para saber como votariam os seus funcionários na eleição presidencial. O blog negou e cobrou a origem da informação falsa. 
Como se vê, a fase em que o blog publicava as respostas antes da publicação da matéria durou apenas oito dias e a migração para domínio próprio pouco mais de dois meses. A lamentar, como falha grave, a perda da memória desta primeira fase em wordpress. Em pesquisa no Google ela é apresentada em primeiro lugar, mas é apenas uma página que encaminha para o novo endereço. Todo o conteúdo teria migrado para o novo domínio, mas, os links originais não foram mantidos. Citações deles resultam em mensagem de erro. Um problema grave de documentação.

Apesar das análises entusiastas com a novidade da relação fonte-jornalista, as questões substantivas da CPI da Petrobras estiveram praticamente ausente dos debates. O foco das análises referiram-se sempre no blog em si e no seu significado.

Já em 14 de junho, o ombudsman da Folha Carlos Eduardo Lins da Silva observa, em sua coluna, acerca de uma matéria que no entender dele não mereceria o destaque que teve na primeira página do jornal: “Ao longo da semana, a relação entre a Petrobras e o MBC foi deixada de lado (o que parece confirmar a sua pouca relevância) e o debate, injustificadamente histérico, se concentrou na criação do blog Fatos e Dados pela estatal." Na opinião do colunista, tal procedimento prejudicaria mais à própria Petrobras por este ser sido utilizado mais para "atiçar a fogueira do conflito sectário que envenena o ambiente político nacional em prejuízo de todos" (Lins da Silva, FSP, 14/06/2009)".

O blog da Petrobras concordou com o comentarista ao reconhecer que este debate levou à interpretação equivocada de que o objetivo da Petrobras seria editar o noticiário e intimidar os profissionais de imprensa (blog da Petrobras, 14/06/2009).

Dos diversos comentários sobre o tema à época, vale destacar um artigo de Claudio Weber Abramo no Observatório da Imprensa onde antecipa que o caso seria temporário, duraria apenas enquanto houvesse a CPI e que o interesse da Petrobras em tal ação consistia numa "reação à CPI montada para investigar as suas operações".

Abramo observa uma questão praticamente ausente nos trabalhos acadêmicos sobre o caso, que é o fato da empresa possuir ações em bolsas de valores, o que provoca tensão com os veículos locais, uma vez que a Petrobras não poderia "prescindir da chamada 'grande imprensa', porque os investidores do mercado não lêem o Democrata de Xixirica da Serra, mas o Globo, o Estadão, a Folha, o Valor (ABRAMO, 2009)".

$\mathrm{Na}$ opinião de Abramo, a iniciativa da Petrobras poderia ainda ajudar a melhoria da qualidade da imprensa, continuando a publicar suas versões, "após os veículos terem publicado as suas histórias"; reconhecendo, entretanto, que tais condutas, possivelmente, sofreriam recuo por 
parte da empresa, até pelo fato das mesma constituírem num caso de deselegância com a imprensa local, conduta que, provavelmente, seria difícil de ocorrer com os veículos internacionais, como a Reuters, a Associated Press, o Financial Times, a Economist, que dificilmente poderiam ser "furados" pelo blog da empresa. Observa ainda que o blog não teria condições de fazer o mesmo com as notícias 'plantadas' por sua assessoria de imprensa” (ABRAMO, 2009).

Como se verá, o comentário referente às matérias "plantadas" era pertinente, fato constatado em de 16 de fevereiro de 2012, quando a jornalista Miriam Leitão em sua coluna "Panorama Econômico", publicada em $O$ Globo, faz um artigo intitulado "Desatar os nós" (LEITÃO, 2012) onde avalia os desafios da Petrobras baseada, conforme a própria matéria informa, em uma conversa com o diretor financeiro Almir Barbassa. Essa entrevista não foi publicada no blog da empresa.

Diariamente o blog publica uma seção intitulada "Destaques internacionais" com um clipping das principais matérias onde a empresa é citada naquele dia. Em breve pesquisa, observa-se que a empresa aparece com frequência em vários jornais de todas partes do mundo, sites e agências de notícias. As respostas às perguntas formuladaas para essas matérias não estão no blog.

Passado o impacto inicial, dois anos depois, já em 24 de maio de 2011, Carlos Castilho ponderava no Observatório da Imprensa que a experiência não era exatamente inovadora, uma vez que já vinha sendo realizada "há quase três anos em governos como os dos Estados Unidos", sendo que Israel foi o primeiro a "entrar para valer na blogosfera", em 2006, quando lançou uma série de blogs "patrocinados pelos ministérios da Defesa e Relações Exteriores”, um deles produzido em Nova York pelo consulado local.

\section{Na academia}

O debate acadêmico sobre o caso foi bastante rico, como bem demonstra a relação de 20 trabalhos citados, apresentados todos nas Referências. Apresentamos aqui apenas os mais significativos, por limitações de espaço.

Ricardo de Souza, (SOUZA, 2011) trata o caso exclusivamente na visão estrita da gestão de imagem. O autor observa que o blog, quando criado teria objetivos claros de tornar-se um canal de comunicação rápida com o público, considerando o "posicionamento da Petrobras sobre as questões relativas à CPI e esclarecimentos solicitados pela imprensa”.

A administração do blog foi realizada por uma equipe de profissionais de comunicação da Petrobras comprometida com seus objetivos, visão, missão e diretrizes; reforçando o "objetivo da 
Petrobras de sempre prestar esclarecimentos à sociedade e alcançar o máximo de transparência possível no relacionamento com seus públicos”.

No entendimento do autor, a empresa passa a se utilizar da ferramenta para fornecer explicações aos questionamentos da CPI e dos jornalistas. O blog, assim, procura acompanhar a tendência da interatividade e velocidade de circulação de informações no mundo globalizado e moderno. Ainda faz referência ao fato do blog se destinar aos internautas, "estimulando o acompanhamento da transmissão ao vivo das sessões da CPI, e no site da Agência Petrobras de Notícias - direcionado exclusivamente para jornalistas - apareciam matérias com o resumo dos depoimentos dos representantes da Petrobras".

O autor é jornalista e faz parte da equipe de profissionais de comunicação da empresa. Seu trabalho não faz referência ao fato de que a empresa contratou, sem licitação, a CDN, grande empresa de comunicação corporativa, para assessorá-la especificamente na crise decorrente da CPI. A CDN se apresenta como empresa "fortemente competitiva e $100 \%$ focada no valor da imagem e da reputação, ativos essenciais para os clientes para integrar os serviços em um mesmo espaço físico".

Marcelo Träsel (TRÄSEL, 2009) apresenta seu trabalho já em novembro de 2009 e ousa uma análise do fenômeno "a quente", apresentando o caso de forma bem organizada e estruturada. E sua análise acreditava que algumas questões relacionadas ao seu trabalho poderiam surgir posteriormente, mas os pontos de análise que realizava estariam suficientemente consolidados. Träsel entende que o caso "simboliza e materializa tensões introduzidas nas rotinas de produção jornalística pela comunicação via rede mundial de computadores”, provocando uma revisão das práticas profissionais e uma revisão na discussão dos valores-notícia; cujo debate sobre legalidade e moralidade da divulgação de perguntas e respostas enviadas pela Petrobras a jornalistas seria, de fato, um embate que contrapunham interesses entre a cultura profissional jornalística e os da sociedade brasileira". Sobre a relação jornalista-fonte, o autor afirma que nas redes de comunicação via computadores e telefonia móvel, as fontes já não dependiam dos jornalistas, pois as circulações de informação estavam disponíveis a qualquer indivíduo com acesso à Internet. As fontes poderiam divulgar as informações que lhes conviessem, assim como o público passaria a acessá-las diretamente, acompanhando os releases dos websites de das empresas, instituições e órgãos do governo ou encontrando-os através das ferramentas de busca (TRÄSEL, 2009).

Esse processo corrobora o enfraquecimento do monopólio da imprensa que subverteria a relação entre jornalistas e fontes e a redução do poder dos repórteres frente às assessorias de 
imprensa e autoridades, uma vez que ambos poderiam atingir o público diretamente, através de ferramentas de comunicação mediada apenas pelo computador. Os jornalistas perderiam poder mesmo frente ao cidadão, que pode divulgar informações diretamente através dos "canais de webjornalismo participativo" (TRÄSEL, 2009). Por fim considera que cada vez mais organizações e indivíduos passem a publicar a íntegra de suas declarações à imprensa e respostas a matérias, quando identificarem distorções e imprecisões resultantes do trabalho de edição. "É premente, por isso, a necessidade de reavaliação, por parte de redações e da academia, das relações entre jornalistas e fontes, bem como das práticas profissionais". (TRÄSEL, 2009)

Antonio Fausto Neto (FAUSTO NETO, 2009) também publica artigo ainda em 2009. Observa o que chama de certo "deslocamento de atividades do ambiente jornalístico para o âmbito de instituições e de atores sociais". Fausto Neto relembra também o afastamento do então ombudsman Carlos Eduardo Lins da Silva em pela discordância em relação à decisão da Folha de S. Paulo de não mais tornar pública a crítica diária produzida por ele. Mais ousado, entende que o processo da midiatização afeta a cultura jornalística, o ambiente produtivo, as rotinas e a própria identidade profissional. Os efeitos da midiatização proporcionariam às instituições e indivíduos acesso, manejo de equipamentos e operações midiáticas, convertendo-os em novos personagens da "codificação da realidade".

Para o autor, uma nova "nova economia enunciativa" rege o ato jornalístico como agendas das fontes; são objetos de decisões de tribunais; viram estratégias de preocupações mercadológicas e se convertem também em objeto de reflexão do campo jornalístico, compartilhando-as com o próprio leitorado. “Ou seja, o sistema jornalístico, enquanto uma 'realidade da construção', no dizer de Luhmann, vira assim, acontecimento". Nesta nova realidade "fontes investem em operações e regras, pondo em xeque a regência unilateral do ato jornalístico de produção da realidade”.

Ademais, 'amplia-se o trabalho sobre o 'controle da edição', na medida em que o processo de produção da notícia pode também ser 'vistoriado' para não dizer, enunciado de outra forma pela fonte". Isso significa que "o processo intenso de midiatização produz repercussões muito complexas nas relações entre os campos sociais, e no caso do campo jornalístico, no status dos seus peritos os jornalistas - e em suas performances simbólicas. Gera múltiplos processos de afetações sobre as estruturas mediadoras de contato entre instituições e atores sociais."

A atividade autoral do jornalista passaria a ser permeada por enunciações heterogêneas, gerando mutações que afetam um dos aspectos centrais da natureza do trabalho jornalístico, que se refere ao seu 'lugar de fala'. Sem perder de todo a característica de seu trabalho enunciativo pode 
verificar que a existência dos processos criados pelas novas condições, reformularia a concepção da autonomia da prática jornalística que edificaria seu ethos (FAUSTO NETO, 2009).

Edson Dalmonte publicou um artigo sobre o blog em 2010 (DALMONTE, 2010) e prosseguiu no debate em trabalho apresentado em 2011 (DALMONTE, 2011). No primeiro, observa que apesar da variedade de plataformas atuais, o fazer jornalístico mantêm atribuições que lhe são peculiares na seleção dos assuntos, abordagens, tratamento, compromisso com o interesse público. Tais atribuições determinam audiências e a veiculação do que está na que está na ordem do dia. Para o autor, o jornalismo é ainda "o grande articulador de discursos" e promove o debate público, "que se provisiona no material fornecido pela instância jornalística que, em tese, se coloca de forma isenta diante dos fatos" (DALMONTE, 2010).

Assim, o blog da Petrobrás apenas amplia a discussão da realidade potencializando formas de comunicação com o cidadão comum. Daí, a tentativa de desqualificação do blog traz uma negação da ideia de liberdade, que caracteriza os processos comunicacionais na Internet e o temor da perda do controle dos processos comunicacionais da mídia tradicional. Esse temor decorre do fato da mídia ter se "colocado como agente mediador, posicionando-se entre o mundo dos fatos e o mundo dos leitores/receptores."

Essa experiência coloca questões para reflexão sobre o status de fonte para provedora de informações e questionamentos sobre o fazer jornalístico, redimensionando a concepção do jornalismo como campo de conflito, uma vez que "os novos aparatos tornam possível a difusão plural de vozes e a participação dos indivíduos no processo de discussão das ideias" (DALMONTE, 2010).

Lemos (LEMOS, 2011) entende que vivemos, hoje, o que chama de nova esfera conversacional, resultado do que chama de nova reconfiguração comunicacional, que em sua perspectiva estaria produzindo um sistema aberto e independente que denominou de "pós-massivo", que estaria se colocando em tensão com o sistema clássico, caracterizado pelo fluxo para as massas. Para o autor, o início do século XXI, estaria gerando um sistema infocomunicacional mais complexo, onde conviveriam formatos massivos e pós-massivos. Sobre a criação do blog da Petrobras, o autor assinala a tensão entre as mídias massivas (jornais) e pós-massivas (blog), como as novas possibilidades de expressão alternativa que se abre para um indivíduo sem intermediário (LEMOS, 2011, p. 6). 


\section{Em 2012}

Passados quase três anos da criação do blog, como estaria se dando a relação entre a empresa e os órgãos jornalísticos da chamada mídia tradicional? A seguir, breves relatos de alguns casos, um de 2011 e todos os demais de 2012.

\subsection{Vazamento de 160 barris de óleo em poço do pré-sal}

No dia 31 de janeiro o blog informava que a empresa detectara um vazamento de óleo em poço do pré-sal na bacia de Santos. O blog continuou dando informações sobre o vazamento e as providências tomadas durante os dois dias seguintes com textos curtos e enfáticos. Tratava-se do primeiro caso de vazamento de óleo em poços do pré-sal. Os jornais fizeram uma cobertura correta e discreta. A Folha de S. Paulo buscou informações adicionais com o Ibama e os sobrevoos para tomadas de imagens para telejornais se deram em aeronaves da própria Petrobras. O caso durou três dias. Os casos dos vazamentos da Chevron no golfo do México e no litoral brasileiro foram lembrados, mas não houve exploração maior. O caso evidenciou que vazamentos são possíveis mas que a Petrobras tem o instrumental necessário para contê-los sem maiores problemas. Nenhum jornal fez nenhuma pergunta à empresa.

\subsection{ONGs e revista Época}

No dia seguinte à mudança de comando na Petrobras, 16 de fevereiro de 2012, a revista Época publica matéria intitulada "Acarajés quentes no tabuleiro da "Graciosa"”. A matéria refere-se ao que qualifica de "dois acarajés quentíssimos". Eles teriam sido "deixados sobre sua mesa por seu “antecessor direto, o petista José Sergio Gabrielli, e referem-se a duas denúncias de desvio de recursos da empresa para irrigar campanhas do PT na Bahia, terra natal de Gabrielli”. Para a revista, "na Bahia, acarajé quente é sinônimo de bastante apimentado". Recurso linguístico original: Época poderia usar "pepino" ou "abacaxi", criou um neologismo. A ironia inclui também o apelido "Graciosa" que Dilma Rousseff usou na posse para referir-se à Maria da Graça Forster, que assumira a presidência da empresa no lugar de Gabrielli no dia anterior. Logo no segundo parágrafo, a revista observa que "não há elementos que envolvam diretamente Gabrielli com as duas denúncias narradas a seguir. Mas os dois episódios ocorreram em sua gestão, e ele pouco ou nada fez para saná-los" (grifos nossos). O primeiro deles seria o uso indevido de recursos de uma 
ONG chamada Pangea, iniciados em 2004, ainda antes da gestão Gabrielli, mas que tiveram 11 contratos assinados no período em que Gabrielli a presidia. O segundo trata de uma demissão de servidor. Sobre o primeiro, a revista informa que "De acordo com documentos da ControladoriaGeral da União (CGU), a que ÉPOCA teve acesso com exclusividade (grifo nosso), boa parte do dinheiro repassado pela Petrobras à Pangea foi desviada. A CGU suspeita de que parte desses recursos tenha ido parar no caixa dois de campanha do PT na Bahia".

Um confronto entre a matéria e a série de três perguntas encaminhadas pela revista nos dias 2, 9 e 16 de fevereiro de 2012 mostra um diálogo de surdos. A primeira pergunta do primeiro questionário do dia 2 de fevereiro questiona: "O que a Petrobras pode dizer a respeito dos desvios de dinheiro? A companhia fiscalizou a aplicação dos recursos? Em caso negativo, por que não?” Já na primeira resposta no blog, a estatal afirma que "Nos contratos de patrocínio, não há prestação de contas no sentido de verificação por parte da Companhia da destinação de cada recurso repassado. Como já dito, a Petrobras verifica a execução do projeto e o cumprimento das contrapartidas de imagem para garantir a visibilidade de sua marca". A empresa confirma que um empregado demitido por justa causa há três anos permanece nos quadros da empresa, remunerado, em licença médica.

\subsection{Caso O Globo - TCU}

No dia 22 de janeiro, o jornal $O$ Globo publicou uma matéria intitulada "TCU vai fazer pente-fino na Petrobras onde informa que o Tribunal de Contas da União vai promover uma varredura nos contratos assinados pela Petrobras. A matéria acrescenta que "Segundo o Tribunal, a empresa tem desrespeitado regras de contratação". Seguem os dados fundamentais: "Maior estatal brasileira, a Petrobras assinou no ano passado contratos que somam $\mathrm{R} \$ 16,3$ bilhões sem qualquer tipo de concorrência ou tomada de preços com fornecedores, o que representou quase um terço da contratação de serviços da companhia ( $\mathrm{R} \$ 52$ bilhões). O valor equivale ainda a $19 \%$ dos $\mathrm{R} \$ 84,7$ bilhões em investimentos previstos pela empresa em 2011. "Se levarmos em conta os últimos três anos, as contratações sem concorrência engordaram as contas bancárias de prestadores de serviços em R \$ 49,8 bilhões".

A seguir, uma informação importante jornalisticamente: "Os dados foram compilados pelo GLOBO com base em cerca de 20 mil contratos de serviços - construção, projetos, instalações de equipamentos e manutenção, por exemplo — disponíveis no site da estatal (grifos nossos)". 
A matéria ouve Claudio Weber Abramo, diretor-executivo da ONG Transparência Brasil e mais quatro advogados e especialistas. Nas perguntas encaminhadas à empresa, o jornal pede informação sobre sete contratos realizados sem licitação, identificados uma a um, pedindo esclarecimentos sobre as razões da não licitação. A empresa não esclarece a razão da não licitação de cada contrato; limita-se a dizer cumprir a legislação. As perguntas eram claras, tratavam de contratos especificados mas a resposta foi insatisfatória. A matéria não informa isso.

\subsection{A sonda enterrada}

No dia 9 de fevereiro, dia da posse da nova presidente da Petrobras, Maria da Graça Forster, a Folha publica matéria intitulada "Petrobras enterrou máquina de R\$ 51 mi”. A matéria fazia referência a uma sonda que ligaria a bacia da Santos a Taubaté que foi abandonada em função de atraso na obra. A Petrobras avaliou que o prejuízo decorrente do atraso seria de R 700 milhões, razão pela qual a sonda inicialmente contratada foi abandonada. As perguntas e respostas no blog são muito mais esclarecedoras do que as matérias. O título da matéria, como se vê, é provocador, mas o fato é confirmado pela empresa.

\subsection{0 preço da gasolina}

Em artigo intitulado "Desatar os nós" de Miriam Leitão em15 de fevereiro de 2012, publicada pelo jornal $O$ Globo, a colunista apresenta um alentado exercício de reflexão sobre as variáveis que determinam o preço da gasolina. Na matéria, essencialmente analítica, as variáveis eram: 1 - a impopularidade de um reajuste do preço da gasolina; 2 - o prejuízo da empresa em importar gasolina a um preço maior daquele que cobra das distribuidoras (o Brasil é autossuficiente na produção de petróleo, mas precisa importar gasolina); 3 - a evidência de subsídio no preço da gasolina; 4 - a queda de $8 \%$ no preço das ações da Petrobras com a informação do lucro da empresa em 201; 5 -o aumento de $24 \%$ no consumo de gasolina no ano de 201; 6 - o aumento de $36 \%$ no consumo de gasolina em janeiro de 2012 comparativamente a janeiro de 2011; 7 - o prejuízo deste tipo de operação que aumenta o déficit da balança comercial; 8 - a queda do dólar atenua prejuízo; 9 - a oscilação do preço do petróleo que estava a US\$ 31 em 2003 e em 2008 chegaria a ultrapassar US\$ 140. Na data do artigo estava em US 112; 10 - as distribuidoras compravam a gasolina a R\$ 1,55 em 2005; hoje compram a $\mathrm{R} \$ 1,51 ; 11$ - o prejuízo foi absorvido pela redução da Cide (imposto sobre combustível). Esta matéria evidencia a complexidade dos problemas nas quais uma empresa do porte da Petrobras enfrenta. O blog não faz referência á matéria nem á conversa entre 
jornalista e fonte, diretor-financeiro da empresa, com nome citado na matéria. Foi uma entrevista "exclusiva".

\subsection{Gabrielli na mesa}

José Sérgio Gabrielli foi o entrevistado de uma seção intitulada à mesa com Valor, em 4 de novembro de 2011, seção em que o jornal reporta um almoço entre jornalista e o presidente às vésperas de abandonar o cargo. Nenhuma referência ao blog. Texto descontraído, mas com muita informação relevante sobre a empresa que foi presidida por ele durante quase nove anos. Vale a referência pelo tratamento correto que o jornal dá à empresa, sem as provocações dos demais jornais e revistas. O blog postou no dia 5 os links para a matéria.

\subsection{Gabrielli na Roda Viva}

No dia 6 de fevereiro de 2012, José Sérgio Gabrielli é o entrevistado do programa Roda Vida, da TV Cultura. A entrevista permite conhecer bem a atual realidade da empresa. Claudio Weber Abramo é duro e questiona de forma incisiva, confirmando as informações da matéria de $O$ Globo sobre a "varredura do TCU”. O blog não faz referência. Em entrevista anterior no dia 8 de junho de 2009, durante os trabalhos da CPI, o blog noticiou e estimulou a participação de internautas ao vivo.

\section{Considerações Finais}

É inquestionável que o jornalismo vive um momento de grandes transformações e que as relações jornalista-fonte é uma das mais afetadas. Isso já se dá em vários tipos de coberturas mais corriqueiras, que não é o caso de exemplificar. Mas, como se vê nos casos relatados, as matérias continuam sendo feitas ainda num padrão convencional de jornalismo. O comportamento da chamada mídia tradicional mantém certa implicância com a empresa, com exceções de jornais como Valor Econômico. As primeiras avaliações, como se viu, mostraram aspectos marcantes das novas configurações do fazer jornalístico. Mas as vinculações desta nova realidade à experiência do blog da Petrobras pareceram exageradas.

O blog de fato significou uma mudança de comportamento. Mas no seu primeiro momento foi mais uma reação ao comportamento agressivo da mídia diante da CPI. A partir da decisão de só publicar as respostas à zero hora do dia em que a matéria será publicada a experiência de fato tornou-se um modelo de transparência e uma alternativa de uma forma direta de relação com o 
público. Três anos depois, o que parecia uma novidade se tornou rotina na atividade da Petrobras e o interesse do público diminuiu. No dia em que se encerrava a redação deste trabalho, a nova presidente da Petrobras, Maria das Graças Forster anuncia que irá responder perguntas de internautas no blog.

\section{Referências}

APRESENTAÇÃO do site da CDN. Disponível em: <http://www.grupocdn.com.br/lang/pt/ institucional/apresentacao/>. Acesso em: 16 jan. 2012.

ARAGÃO, Rodrigo Martins. Redesenhando o ecossitema da comunicação: mídias sociais e o blog da Petrobrás. In: SOCIEDADE BRASILEIRA DE ESTUDOS INTERDISCIPLINARES DA COMUNICAÇÃO, 32., 2009, Curitiba: INTERCOM Júnior, 2009.

LICITAÇÃO: resposta ao jornal O Globo, 22 jan. 2012. In: Fatos e dados, blog da Petrobras. Disponível em: <http://fatosedados.blogspetrobras.com.br/2012/01/22/licitacao-resposta-ao-jornalo-globo/>. Acesso em: 16 jan. 2012.

PATROCÍNIO e demissão: respostas à revista Época, 17 fev. 2012. In: Fatos e dados, blog da Petrobras. Disponível em: <http://fatosedados.blogspetrobras.com.br/2012/02/17/patrocinio-edemissao-respostas-a-revista-epoca/>. Acesso em: 17 fev. 2012.

AO VIVO: assista e participe da entrevista do presidente Gabrielli no Roda Viva, 8 jun. 2009. In:

Fatos e dados, blog da Petrobras. Disponível em: <http://fatosedados.blogspetrobras.com.br /2009/06/08/ ao-vivo-assista-e-participe-da-entrevista-do-presidente-gabrielli-no-roda-viva/>. Acesso em: 8 de junho de 2009.

CONFIRA a entrevista com de Gabrielli ao Valor, 05 nov. 2012. In: Fatos e dados, blog da Petrobras. Disponível em: <http://fatosedados.blogspetrobras.com.br/2011/11/05/confira-aentrevista-de-gabrielli-ao-valor/>. Acesso em: 16 jan. 2012.

LEITORES do blog entrevistam Graça Foster, 2 mar. 2012. In: Fatos e dados, blog da Petrobras.

Disponível em: <http://fatosedados.blogspetrobras.com.br/2012/03/02/leitores-do-blog-entrevistamgraca-foster/>. Acesso em: 02 mar. 2012.

PETROBRAS não pergunta aos seus empregados em quais candidatos eles votam em 28 de julho de 2010. In: Fatos e dados, blog da Petrobras. Disponível em: <http://fatoedados.blogspetrobras. com.br/2010/07/28/petrobras-quer-saber-lauro-jardim-de-onde-voce-tirou-isso/>. Acesso em: 16 jan. 2012.

PETROBRAS pergunta ao Correio Braziliense, 26 jun. 2009. In: Fatos e dados, blog da Petrobras. Disponível em: <http://fatosedados.blogspetrobras.com.br/2009/06/26/petrobras-pergunta-aocorreio-braziliense/>. Acesso em: 16 jan. 2012.

PETROBRAS pergunta ao jornal O Globo, 25 jun. 2009. In: Fatos e dados, blog da Petrobras. Disponível em: <http://fatosedados.blogspetrobras.com.br/2009/06/25/petrobras-pergunta-aojornal-o-globo/>. Acesso em: 16 jan. 2012.

OMBUDSMAN da Folha e o blog da Petrobras, 14 jun. 2009. In: Fatos e dados. Disponível em: <http://fatosedados.blogspetrobras.com.br/2009/06/14/ombudsman-da-folha-e-o-blog-dapetrobras/>. Acesso em: 16 jan. 2012.

CABRAL, Eugênia. Direto à fonte: a participação do público no blog da Petrobras. SBPJor. VIII Encontro Nacional de Pesquisadores em Jornalismo. Maranhão: UFMA. Novembro de 2010. CASTILHO, Carlos. Observatório da imprensa: polêmica sobre o blog da Petrobras mostra o surgimento de um novo espaço público para debates no país em 24/05/2011. Disponível em: 
<http://www.observatoriodaimprensa.com.br/posts/view/polemica-sobre-o-blog-da-petrobrasmostra-o-surgimento-de-um-novo-espaco-publico-para-debates-no-pais>. Acesso em: 16 jan. 2012. SILVA, Carlos Eduardo Lins da. Muito barulho por quase nada. Folha de S. Paulo, 14 jun. 2009. Disponível em: <http://www1.folha.uol.com.br/fsp/ombudsma/om1406200901.htm>. Acesso em: 16 jan. 2012.

ABRAMO, Claudio Weber. Observatório da imprensa: quando a fonte abre o jogo em 09/06/2009. Disponível em: <http://www.observatoriodaimprensa.com.br/news/view/quando_a_ fonte_abre_o_jogo. Acesso em: 16 jan. 2012.

DALMONTE, Edson Fernando. É preciso ordenar a comunicação?: questionamentos acerca da necessidade de instâncias mediadoras entre a mídia e o público. In: CONGRESSO LUSO AFRO BRASILEIRO DE CIÊNCIAS SOCIAIS, 11., 2011, Salvador. Diversidades e (des)igualdades. Simpósio Temático "Mídia e democracia”. Salvador: UFBA, 07-10 ago. 2011.

DALMONTE, Edson Fernando. O blog da Petrobras e o jornalismo: de que aspectos éticos estamos falando? Brazilian Journalism Research. v. 6, n. 2, p. 59-69, 2010. Disponível em:

<ttp://bjr.sbpjor.org.br/index.php/bjr/about>. Acesso em: 01 fev. 2012.

FAUSTO NETO, Antônio. Jornalismo: sensibilidade e complexidade. Revista Galáxia, São Paulo, n. 18, p.17-30, dez. 2009.

FERREIRA, Antonio Pedro Aragão. Novos desafios para o jornalismo: o caso do blog da Petrobras Fatos e Dados. TCC. Orientação FERREIRA JÚNIOR, José Ribamar, São Luis: UFMA, 2011.

Folha de S. Paulo "CGU aponta desvios de R\$2,8 bi em contratos com ONG. Disponível em: $<$ http://www1.folha.uol.com.br/fsp/poder/26508-cgu-aponta-desvios-de-r-28-bi-em-contratos-comong.shtml>. Acesso em: 16 mar. 2012.

KARAM, Francisco José e SCHMITZ, Aldo Antonio. A ética de lado a lado: fontes de notícias e jornalistas frente a frente. Porto Alegre: Revista INTEXTO. UFRGS, v. 2, n. 23, p. 171-182 julho/dezembro 2010.

LEMOS, André. Nova esfera Conversacional. In: KÜNSCH, Dimas A. D.A; SILVEIRA, S.A. da, et al. Esfera pública, redes e jornalismo. Rio de Janeiro: Editora E-Papers. 2009. Disponível em <http://andrelemos.info/artigos/conversacao.pdf>. Acesso em: 22 fev. 2012.

MAINIERI, Tiago. Os desafios da comunicação organizacional na era das mídias digitais. In: SOCIEDADE BRASILEIRA DE ESTUDOS INTERDISCIPLINARES DA COMUNICAÇÃO, 34., 2011, Recife: INTERCOM Júnior, 2-6 set. 2011.

MEDEIROS, Cecilia. Caso Petrobras x Folha de São Paulo: blog fatos e dados. Trabalho de Iniciação Científica. Orientador: Antonio Fausto Neto. São Leopoldo: UNISINOS, 2010.

MIRANDA, Clarissa Mazon. Estratégias de contra-agendamento em websites e blogs: exemplos de participação do público nos mídia. Trabalho apresentado ao GP de Cibercultura: UFSM/ RS, 2010.

LEITÃO, Miriam. Desatar os nós. O Globo, 16 fev. 2012. Disponível em:

<http://oglobo.globo.com/economia/miriam/posts/2012/02/15/desatar-os-nos-431855.asp>. Acesso em: 16 jan. 2012.

MONTEIRO, Luiz Antônio Cavalcanti. Discursos em torno do Blog Petrobras: fatos e dados. Cadernos do Congresso Nacional de Linguística e Filologia (CNLF), v. 14, n. 4, t. 3, p. 25892599.

MOSCHETTA, Andressa Pacheco; JACOPETTI, Andréia Mendes. Convergência no jornalismo: o caso do blog da Petrobrás. SBPJor - ENCONTRO NACIONAL DE PESQUISADORES EM JORNALISMO, 7., São Paulo: USP, nov. 2009.

MOSCHETTA, Andressa Pacheco; MARTINS, Francisco Menezes. Rastros do blog fatos e dados nas redes sociais. SIMPÓSIO NACIONAL DA ABCIBER, 3., São Paulo. Artigo científico 
apresentado ao eixo temático "Jornalismo e novas formas de produção da informação". São Paulo: 2009.

TOTTI, Paulo. Valor Econômico: a estatal aceitou o economista, 4 set. 2011. Disponível em: $<$ http://www.valor.com.br/cultura/1081800/estatal-aceitou-o-economista $>$. Acesso em: 16 jan. 2012.

RESPOSTA da Petrobrás para a Folha sobre o mesmo caso. In: Fatos e dados, blog da Petrobras. Disponível em: <http://fatosedados.blogspetrobras.com.br/2012/02/18/pangea-respostas-a-folha-des-paulo/\#more-50796>. Acesso em: 16 mar. 2012.

CASO Pangea, Revista Época, 16 fev. 2012. Disponível em: <http://revistaepoca.globo.com/ tempo/ noticia/2012/02/acarajes-quentes-no-tabuleiro-da-graciosa.html>. Acesso em: 16 fev. 2012. RUBLESCKI, Anelise. Metamorfoses jornalísticas: leitores e fontes como instâncias coprodutoras de conteúdos no jornalismo líquido. LabCom. Universidade da Beira Interior (Portugal): Estudos em Comunicação, n. 10, p. 319-335, dez. 2011. Disponível em:

<http://www.ec.ubi.pt/ec/10/pdf/EC10-2011Dez-18.pdf>. Acesso em: 01 fev. 2012. SANTOS, Nina Fernandes dos. Esfera de visibilidade e comunicação desintermediada: uma análise do blog fatos e dados. Trabalho de Conclusão de Curso. Orientação GOMES, Wilson. Salvador: FACOM/UFBA, 2010.

SANTOS, Nina Fernandes dos. O blog fatos e dados e sua articulação com a esfera de visibilidade pública. ENCONTRO DE ESTUDOS MULTIDISCIPLINARES DE CULTURA GRADUANDA, 6., Salvador: FACOM/UFBA, 25-27 maio 2010.

SOUZA, Ricardo de. Como vencer uma crise em seis meses. Diálogo ESPM, ano 1, n.1, abr. 2011. Disponível em: <http://dialogo.espm.br/index.php/dialogo>. Acesso em: 16 jan. 2012. TCU vai fazer pente-fino na Petrobras. O Globo, 22 jan. 2012. Disponível em: <http://oglobo.globo.com/economia/tcu-vai-fazer-pente-fino-na-petrobras-3731456>. Acesso em: 16 jan. 2012.

TORRES, Mairon Hothon do Nascimento et al. O blog como ferramenta de comunicação alternativa: o caso do 'blog 'fatos e dados' da Petrobras. In: SOCIEDADE BRASILEIRA DE ESTUDOS INTERDISCIPLINARES DA COMUNICAÇÃO, 34., Recife: INTERCOM Júnior, 2011.

TRÄSEL, Marcelo. Comunicação mediada por computador e newsmaking: o caso do blog da Petrobras. In: SOCIEDADE BRASILEIRA DE ESTUDOS INTERDISCIPLINARES DA COMUNICAÇÃO, 32., Curitiba: Congresso INTERCOM, 3-7 set. 2009. 